\title{
Role of Electronic Prescription in the Reduction of Prescription Error Rate: A Systematic Review
}

\author{
Tantri Puspa Ditya, Wiku Bakti Bawono Adisasmito \\ Study Program of Hospital Administration, Faculty of Public Health, \\ Universitas Indonesia
}

\begin{abstract}
Background: Prescription errors are a big problem in the world. The concept of medication safety began to become a global concern since November 1999 after the Institute of Medication (IOM) reported an unexpected event of medication error in America. Electronic Medical Record (EMR) has the potential to reduce instances of medication error and improve communication between pharmacist and prescriber. This study aimed to systematically review the role of e-prescription in the reduction of prescription error rate.

Subjects and Method: This was a systematic review using articles from 3 electronic databases, namely PubMed, Google Scholar, and Medline. The keywords used in the study were e-prescription, electronic prescription, medication error, hospital formulary, and hospital. The articles under review were taken from observational studies conducted in hospital involving EMR (electronic prescription). These articles were published from 2015 to 2019. The main outcome was the incidence of prescription error. Steps in conducting systematic review followed PRISMA flow diagram rule.

Results: 6067 articles were obtained for systematic review based on pre-determined keywords. 9 articles met the inclusion criteria. 4 of 9 articles discussed EMR. 5 articles discussed the use of e-prescription with patient safety. In these articles, EMR could help reduce various errors, including difficulty in understanding the doctor's writing. The eprescription through EMR did not run optimally, because it lacked support of prescription tools and compliance by doctors.

Conclusion: The e-prescription can reduce the number of prescription errors and maintain patient safety. The e-prescription through electronic medical record helps doctors to prescribe according to the formulary and provides an overview of the hospital with patterns of drug use. The efforts to maintain patient safety must continue so that patient safety is maintained.
\end{abstract}

Keywords: electronic medical record, e-prescription, medication error, patient safety

\section{Correspondence:}

Tantri Puspa Ditya. Study Program of Hospital Administration, Faculty of Public Health, Universitas Indonesia. Jl. Margonda Raya, Pondok Cina, Beji, Depok-16424, West Java. Email: puspa.tantri@ymail.com. Mobile: 08569951262.

The $6^{\text {th }}$ International Conference on Public Health Best Western Premier Hotel, Solo, Indonesia, October 23-24, 2019 | 242 https://doi.org/10.26911/the6thicph.04.04 